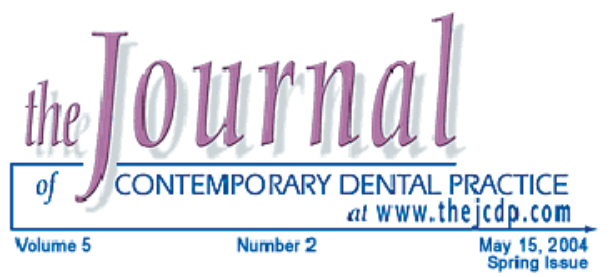

\title{
Assessment of Morphological Changes and Permeability of Apical Dentin Surfaces Induced by Nd:YAG Laser Irradiation through Retrograde Cavity Surfaces
}

\author{
Hacer Deniz Arısu, BDS; Oya Bala, BDS, PhD; \\ Goulnara Alimzhanova, BDS; Emin Türkōz, BDS, PhD
}

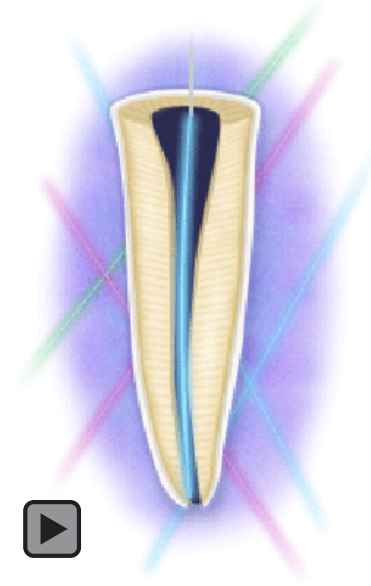

Abstract

The purpose of this in vitro study was to observe the morphological changes and apical dye penetration at apical dentin surfaces induced by Nd:YAG laser irradiation at different power settings with and without a laser initiator. Seventy five single rooted human maxillary anterior teeth were used. Following the establishment of the working lengths, the root canals were enlarged with step-back technique. The apex of each root was resected $3 \mathrm{~mm}$ perpendicular to its long axis. Standard Class I cavities of $2 \mathrm{~mm}$ depth and $2 \mathrm{~mm}$ width were prepared. The teeth were randomly divided into five groups with fifteen teeth in each. In Group 1, the retrograde cavity preparations were lased with Nd:YAG laser at $2 \mathrm{~W}$ and those in Group 2 preparations were lased with Nd:YAG laser at 3.2 W. In Group 3, the retrograde cavity surfaces were lased with Nd:YAG laser at 2 W following the application of India ink. Group 4 was lased with the same settings of Group 2 after an absorbent cotton point soaked with India ink was inserted into the cut dentinal surfaces and the inner walls of the apical preparations. Group 5 served as control. Five teeth from each group were examined using scanning electron microscopy (SEM). The amounts of smear layer, debris, and recrystalized dentin present were assessed and scored. Retrograde cavities of ten teeth from each group were filled with amalgam to examine apical dye penetration. The teeth were immersed in $2 \%$ basic fuscin and kept for 48 hours. Dye penetration was evaluated by stereomicroscope at a magnification of $\mathrm{X} 10$.

(c) Seer Publishing 
The results showed the usage of India ink with Nd:YAG laser enhanced the amount of melting and recrystalization of dentin and the radiation and initiator increased the leakage.

Keywords: Nd:YAG laser, smear layer, recrystalization, ablation, apical leakage

Citation: Arisu HD, Bala O, Alimzhanova G, Türköz E. Assessment of Morphological Changes and Permeability of Apical Dentin Surfaces Induced by Nd:YAG Laser Irradiation through Retrograde Cavity Surfaces. J Contemp Dent Pract 2004 May;(5)2:102-113.

\section{Introduction}

The neodymium:yttrium-aluminum-garnet (Nd: YAG) laser is one of the most popular type of laser applications in dentistry. In endodontic therapy, the Nd:YAG laser is useful for the removal of smear layer and debris ${ }^{1}$, shaping ${ }^{2}$, and bactericidal effect. ${ }^{3,4}$ However depending on the type of laser used and the tissue irradiated, various effects such as ablation, light transmission, scattering, and absorption may occur due to the usage of laser irradiation.
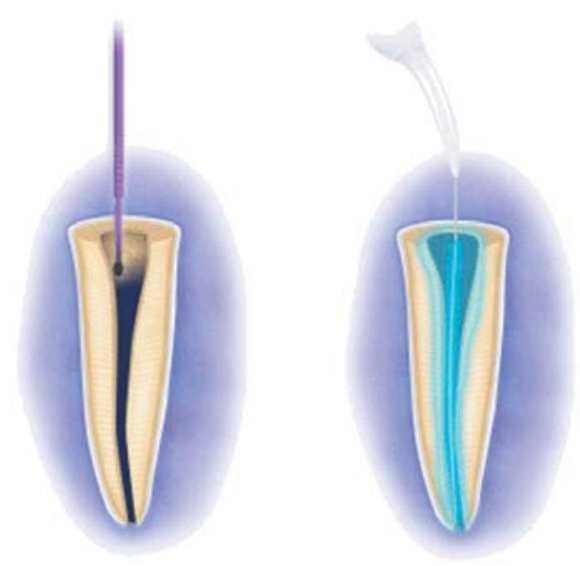

The effects of laser irradiation depend on different factors such as power level, duration of exposure, and color of dentin. There are several studies on different power levels of $\mathrm{Nd}$ :YAG laser in root canal therapy. Dederich et al. ${ }^{1}$ suggest the $\mathrm{Nd}$ : YAG laser irradiation reduces the permeability of the dentin wall in root canal due to the melting of the tissue. Marques et al. ${ }^{5}$ showed the pulsed $\mathrm{Nd}$ :YAG laser has the ability of melting the dentin wall in a root canal using an output of 1 to $3 \mathrm{~W}$. On the other hand, Saunders et al. ${ }^{6}$ had reported that pulsed Nd:YAG laser irradiation with a power of 0.75 to $1.7 \mathrm{~W}$ did not melt the wall of the root canal and failed to remove the debris.
The Nd:YAG laser has a wavelength of 1064 $\mathrm{nm}$. Although the laser light is poorly absorbed by water, this wavelength is easily absorbed by protein, pigmented tissue, and dark surfaces. Consequently, a black dye such as India ink was used in several studies to enhance the effect of lasing. Morioka et al. had compared the absorbance of laser beam at the enamel surface with different black absorbent materials and found a waterproof India ink was the most suitable initiator for pulsed Nd:YAG lasers. ${ }^{7}$ Painting the root canal with India ink was recommended when this laser is to be used for root canal treatment so that more laser energy will be absorbed at the dentin surface. ${ }^{8}$

More recently, the Nd:YAG laser is being used to improve the apical seal after apicoectomy. Stabholz et al. reported the application of the $\mathrm{Nd}$ : YAG laser had reduced apical dye penetration into the teeth after apicoectomy and retrofill. ${ }^{9}$ There is an insuffcient number of studies on laser application in endodontics.

The aim of this in vitro study was to evaluate different aspects of laser application in endodontic surgery.

These include morphological changes on the cut dentinal tubules at the apex induced by pulsed Nd:YAG laser irradiation using two different power settings, with or without a laser initiator (India Ink), and to observe the effect of these changes on the leakage of retrofillings.

\section{Materials and Methods}

\section{Specimens and Preparation}

Seventy five freshly extracted single-rooted human maxillary anterior teeth were collected and kept in physiological saline solution until use. The tooth 


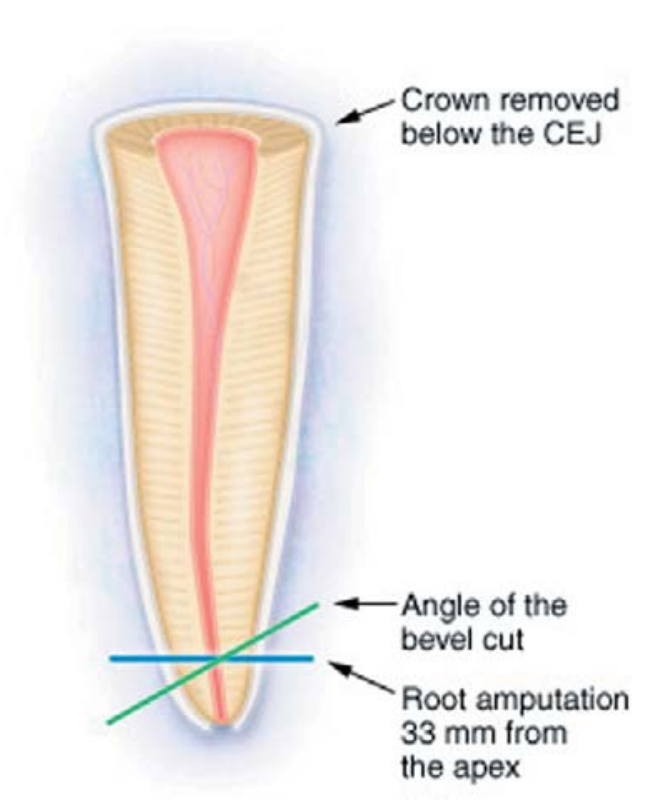

Figure 1. Design of the prepared specimens.

crowns were cut off below the cementoenamel junction with a diamond bur (Busch, Germany) under water coolant. The working length of each root canal was established $1 \mathrm{~mm}$ short of the apical foramen with a \#15 K-file (Zipperer, Germany). Each root canal was cleaned with $5.25 \% \mathrm{NaOCl}$ and $3 \% \mathrm{H} 2 \mathrm{O} 2$, and shaped to a \#40 K-file at working length, using the step-back technique. Then, the root canals were dried with absorbant points (Roeko, Germany) and obturated with gutta-percha (Dia Dent, Korea) and $\mathrm{AH}-26$ (Dentsply, Germany) root canal sealer appropriate for the lateral condensation technique. The tip of each root was resected perpendicular to its long axis $3 \mathrm{~mm}$ from the apex with a diamond fissure bur using a high speed hand piece with water coolant. Then Class I apical cavities with the depth of $2 \mathrm{~mm}$ and the width of $2 \mathrm{~mm}$ were prepared with a \#018 bur (Busch, Germany). (Figure 1)

The teeth were randomly divided into five groups of fifteen teeth in each. Ten teeth in each group were used for leakage studies and the other five teeth were used for scanning electron microscopic (SEM) examinations. The cut apical dentinal surfaces of the experimental groups were lased under different parameters with a pulsed Nd:YAG laser at $1064 \mathrm{~nm}$ (American Dental Technologies, Texas, USA). The laser beam was delivered with a $320 \mathrm{~m}$ in diameter flexible fiber optic cable with its tip held $2 \mathrm{~mm}$ from the cut dentinal surfaces and moved in a circular manner.
Group 1 was lased with 100 mJ, 20 Hz, 2 W energy settings without any laser initiator. The teeth in Group 2 were lased using a power of $3.2 \mathrm{~W}$ with a frequency of $20 \mathrm{~Hz}$ and an energy of $160 \mathrm{~mJ} /$ pulse without any laser initiator. In Group 3, the teeth were irradiated under the same conditions of Group 1 after the cut dentinal surfaces and the inner walls of the apical preparations were painted with an absorbent cotton point soaked with India ink (Pelikan 4001, Hannover, Germany). Group 4 was lased with the same settings of Group 2 after an absorbent cotton point soaked with India ink was inserted into the cut dentinal surfaces and the inner walls of the apical preparations. The laser was activated for $40 \mathrm{~s}$ in all groups. Group 5, which served as the control, was not lased. The roots were kept moist in wet cotton sponges until they were examined using a SEM.

\section{Scanning Electron Microscopy}

Five teeth prepared for SEM in all experimental groups were sectioned longitudinally without any retrofilling; thus, 10 SEM specimens in each group were obtained. The specimens were air dried, mounted on stubs, sputter coated with $0.015 \mu \mathrm{m}$ of gold layer for SEM examination (JSM-840A. JOEL-Technic Co., Ltd., Tokyo, Japan). Serial SEM photomicrographs at $\times 1000$ and $x 1500$ original magnifications were taken from the cut dentinal surfaces at the apex. The amounts of smear layer, debris, and recrystallized dentin presence were then assessed according to the method modified from Gutmann et al. ${ }^{10}$ and Goya et al. ${ }^{11}$ (Table 1).

\section{Leakage}

The lased retrograde cavities of 10 leakage specimens of each group were filled with amalgam (Cavex, Holland) and kept in distilled water at $37^{\circ} \mathrm{C}$ for 24 hours. All root surfaces except the retrograde cavity and $1 \mathrm{~mm}$ from the margins of the restorations were coated with two layers of colored nail polish to prevent dye penetration from this area. After the nail polish was dried, the teeth were immersed in $2 \%$ basicfucsin for 48 hours. Then the teeth were rinsed with distilled water and allowed to dry. The roots were grooved and split longitudinally into two halves. Measurements of the maximum depth of dye penetrations were made under a stereomicroscope (Olympus SZ 40, JAPAN) at 10X magnification. 
Table 1. Criteria for smear layer, debris, and recrystallized dentine evaluation.

\begin{tabular}{|c|c|c|c|}
\hline \multirow{2}{*}{ Score } & \multicolumn{3}{|c|}{ Citeria } \\
\hline & Amount of Smear & Amount of Debris & $\begin{array}{c}\text { Amount of Recrystallized } \\
\text { dentin }\end{array}$ \\
\hline $\mathbf{0}$ & $\begin{array}{l}\text { All dentinal tubules were } \\
\text { open and no smear layer } \\
\text { was present }\end{array}$ & No debris was present & No recrytallized dentin \\
\hline 1 & $\begin{array}{l}\text { Some dentinal tubules were } \\
\text { open and a thin smear layer } \\
\text { covered the openings of cut } \\
\text { dentinal tubules }\end{array}$ & $\begin{array}{l}\text { Few debris particles whose } \\
\text { diameters were less than } \\
20 \mu \mathrm{m} \text { were present }\end{array}$ & $\begin{array}{l}\text { The amount of recrytallized } \\
\text { dentin present covered less } \\
\text { than } 50 \% \text { of the surface }\end{array}$ \\
\hline 2 & $\begin{array}{l}\text { All dentinal tubules were } \\
\text { covered by a thin smear } \\
\text { layer }\end{array}$ & $\begin{array}{l}\text { Large quantities of debris } \\
\text { particles whose diameters } \\
\text { were less than } 20 \mu \mathrm{m} \text { were } \\
\text { present }\end{array}$ & $\begin{array}{l}\text { The amount of recrytallized } \\
\text { dentin present was greater } \\
\text { than } 50 \% \text { of the surface }\end{array}$ \\
\hline 3 & $\begin{array}{l}\text { All the dentinal tubules were } \\
\text { closed by a thick smear } \\
\text { layer }\end{array}$ & $\begin{array}{l}\text { Large amounts of debris } \\
\text { particles whose diameters } \\
\text { were greater than } 20 \mu \mathrm{m} \\
\text { were present }\end{array}$ & - \\
\hline
\end{tabular}

Table 2. Smear layer, debris, and recrystallized dentin scores.

\begin{tabular}{|c|c|c|c|c|c|c|c|c|c|c|c|}
\hline \multirow{3}{*}{ Groups } & \multicolumn{11}{|c|}{ Score } \\
\hline & \multicolumn{4}{|c|}{ Amount of Smear } & \multicolumn{4}{|c|}{ Amount of Debris } & \multicolumn{3}{|c|}{$\begin{array}{l}\text { Amount of } \\
\text { Recrystallized } \\
\text { Dentin }\end{array}$} \\
\hline & 0 & 1 & 2 & 3 & 0 & 1 & 2 & 3 & $\mathbf{0}$ & 1 & 2 \\
\hline Group 1 & 0 & 5 & 0 & 0 & 0 & 4 & 1 & 0 & 0 & 5 & 0 \\
\hline Group 2 & 4 & 1 & 0 & 0 & 4 & 1 & 0 & 0 & 0 & 5 & 0 \\
\hline Group 3 & 5 & 0 & 0 & 0 & 5 & 0 & 0 & 0 & 0 & 0 & 5 \\
\hline Group 4 & 5 & 0 & 0 & 0 & 5 & 0 & 0 & 0 & 0 & 0 & 5 \\
\hline Group 5 & 0 & 1 & 2 & 2 & 0 & 2 & 3 & 0 & 5 & 0 & 0 \\
\hline
\end{tabular}

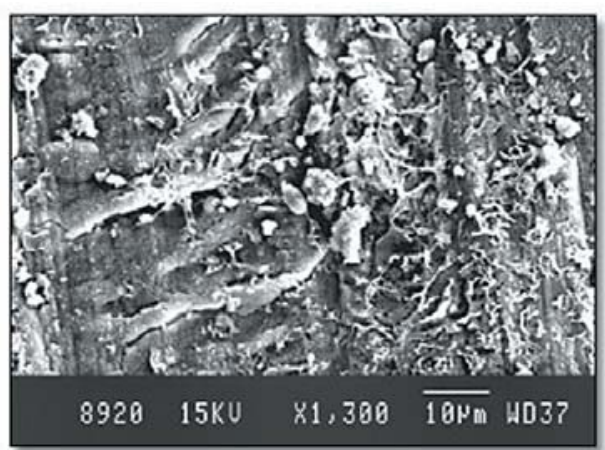

Figure 2. A photomicrograph of a Group 1 specimen showing melted material resembled the appearence of glazed interconnected droplets. 
Statistical analyses were done using variance analysis, Duncan, and Mann-Whitney $U$ tests to determine the differences between groups.

\section{Results}

\section{Scanning Electron Microscopy}

Smear, debris, and recrystallized dentin amounts at cut dentin surfaces for each group are shown in Table 2. In Group 1 specimens, SEM examinations revealed a thin smear layer which cover the cut dentinal surfaces, however, the structural changes were not uniform. There were melted areas as well as non-melted areas that looked like the dentinal smear layer of non-lased specimens of Group 5. Though the diameters were less than $5 \mu \mathrm{m}$, two of the specimens had large quantities of debris particles, while fewer debris particles were observed in the other eight. The appearance of melted material was like glazed interconnected droplets (Figure 2).

SEM examination of Group 2 specimens showed a melted and recrystallized smear layer on the surface as well as the melted and recrystallized dentin surface itself. There were also a few recrystallized dentin areas, but these were not uniform, covered less than $50 \%$ of the surface, and were scored as 1 (Figure 3). The irradiation parameters in this group seemed to be sufficient for vaporizing debris and tissue remnants from the cut dentinal surfaces. Only two of the specimens had a thin smear layer and few debris particles.

In Group 3 and Group 4 the cut dentinal surfaces irradiated by Nd:YAG laser in combination with a laser initiator were very different from the other groups. SEM examination of lased dentin showed dense melting followed by solidification and recrystallization of the hard tissue. The surfaces with open dentinal tubules were surrounded with areas covered with melted mineral globules with a cracked appearence and dentinal tubules sealed by fusion of dentin. (Figures 4, 5) In Group 4 specimens, crumbling and fissures on the cut dentinal surfaces were observed.

In non-lased specimens (Group 5) an amorphous smear layer and large quantities of debris particles on the cut dentinal surfaces were observed. (Figure 6)

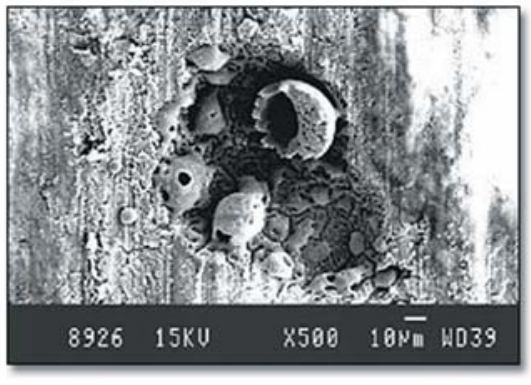

Figure 3. A photomicrograph of a Group 2 specimen showing melted and recrystallized mineral globules covered less than $50 \%$ of the surface.

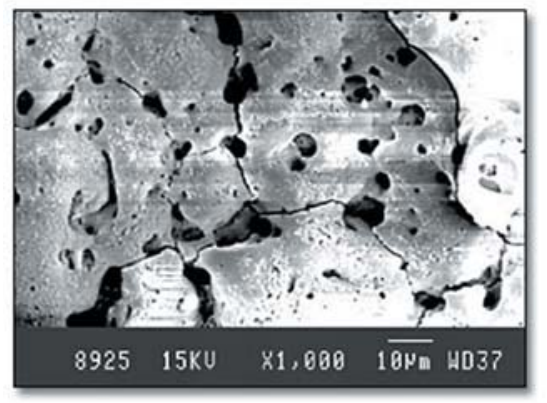

Figure 4. A photomicrograph of a Group 3 specimen showing melted and recrystallized dentin and cracks.

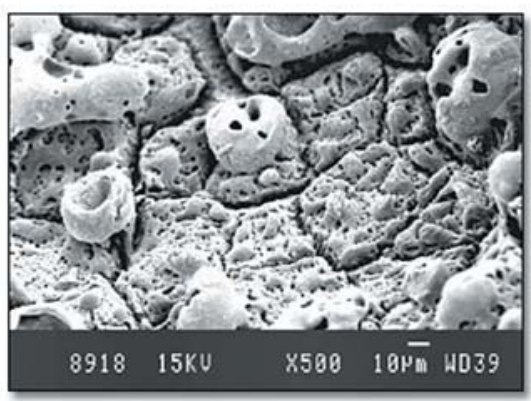

Figure 5. A photomicrograph of a Group 4 specimen showing melted dentin with some mineral globules and fissures.

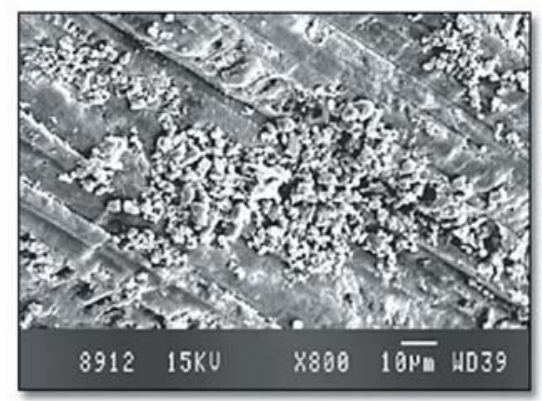

Figure 6. SEM photomicrograph of a non-lased specimen showing large quantities of debris particles with diameters less than $20 \mu \mathrm{m}$. 
Table 3. Means and standard deviations of the apical leakage of experimental and control groups.

\begin{tabular}{|l|l|}
\hline Groups & Means and standard deviations \\
\hline \hline Group 1 & $2.88 \mu 1.76$ \\
\hline \hline Group 2 & $5.55 \mu 1.58$ \\
\hline Group 3 & $6.00 \mu 1.24$ \\
\hline Group 4 & $5.25 \mu 1.58$ \\
\hline Group 5 & $2.70 \mu 1.33$ \\
\hline
\end{tabular}

\section{Leakage}

Table 3 shows the mean and the standard deviations of apical dye penetration of control and experimental groups. Statistical analysis showed there was no significantly different microleakage between Group 5 (control) and Group 1, while the differences between the control group and other groups were statistically significant $(p<0.05)$. The differences between experimental groups among themselves were also not significant ( $p>0.05)$. (Table 4)

\section{Discussion}

Success on the clinical usage of Nd:YAG lasers largely depends on the wavelength, output power, pulse duration, exposure time, spot size, type, and colour of tissue which will be irradiated. ${ }^{12,13}$

The $1064 \mathrm{~nm}$ radiation emitted by the Nd:YAG laser is primarily absorbed by dark pigments. Enhancement of laser beam absorbtion could be achieved by using surface agents. ${ }^{14,15,16}$ White et al. reported threshold levels for dentin removal could be lowered with the use of dyes. ${ }^{17}$ McDonald et al. used Nd:YAG lasers on cut dentinal surfaces and reported that crater depth increased in the presence of a black dye. ${ }^{18}$ Dederich et al. ${ }^{19}$ used India ink to stain the dentin surface in a study which attempted to observe the fusing effects of Nd:YAG laser. Ramsköld et al. ${ }^{20}$ and Rooney et al. ${ }^{4}$ used a black dye (Nigrosin) to stain microorganisms; they found the bacterisidal effect of Nd:YAG laser was increased by using this dye. Zang et al. evaluated the effects of intracanal Nd:YAG laser irradiation with or without
Table 4. Significant correlation between apical dye penetrations of control and experimental groups.

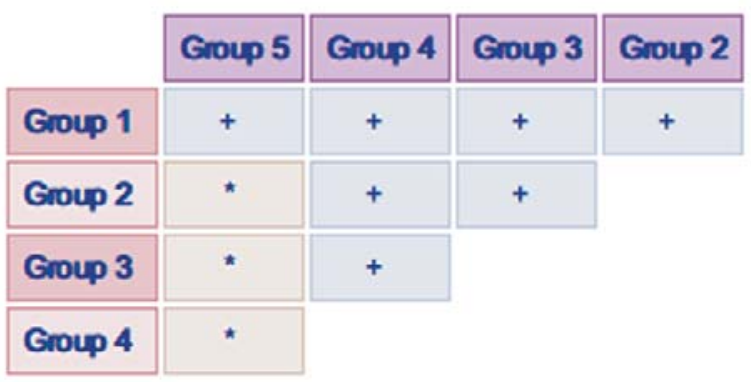

+ no statistically significant difference $(p>0.05)$

* $\quad$ statistically significant difference $(p<0.05)$

initiators such as black ink and $38 \% \mathrm{Ag}\left(\mathrm{NH}_{3}\right)_{2} \mathrm{~F}$ on dentin permeability; they found black ink was more effective than $38 \% \mathrm{Ag}\left(\mathrm{NH}_{3}\right)_{2} \mathrm{~F}$ as a $\mathrm{Nd}$ :YAG laser initiator. ${ }^{8}$ Morioka et al. tested different black absorbant materials to absorb the laser beam at the enamel surface and found water proof India ink was the most suitable initiator for pulsed $\mathrm{Nd}$ : YAG laser.

In our study we observed India ink was an effective initiator for Nd:YAG laser, and it enhanced the structural changes on the cut dentinal surface. However, these changes were not uniform. This might be because of the non-uniform energy distribution from the laser beam. Another factor which might effect this situation can be the non-uniform India ink staining of the dentinal surfaces. Structural changes in non stained groups were also nonuniform. The reason for this situation might be the increase at the absorptive feature of charred dentinal surfaces. These observations are in a coincidence with the findings of Zang et al. ${ }^{8}$ and Stabholz et al. ${ }^{21}$

The effects of Nd:YAG laser on the apical leakage of resected roots were evaluated by Stabholz et al. ${ }^{21}$ It was shown that application of Nd:YAG laser reduced the permeability of resected dentin surfaces to dyes. In contrast to this, we observed an increased permeability to dye penetration in almost all of the lased groups. This was in agreement with the findings of Pashley et al. ${ }^{22}$ who reported increased permeability was due to 
the thinning of dentin through crater formation and incomplete glazing of the crater surface. They also reported permeability was confined to the halo region around the laser crater where tubules were open. We also observed some crater formations and radial cracks on dentinal surfaces at SEM examination. The rise in temperature of the dental tissue is often so great during and after lasing that undesirable morphological changes such as cracks may occur during the cooling stage. ${ }^{23}$ All of these structural changes might be the reason for increased dye penetration.

Leakage through dentinal tubules can also be influenced by the angle of the bevel prepared on the apex and the depth of root end preparation. ${ }^{24}$ To faciliate root end preparations and placement of retrofilling materials, apecies are usually beveled with an angle. To eliminate the effect of this variable the root ends were cut perpendicular to the long axis of the roots. The perpendicular, non-beveled cuts provided better reference points to determine the amount of dye penetration.

In this study we preferred to use a $2 \%$ basicfucsin solution because of its red colour, in order to differentiate initiator dyes easily.
When Nd:YAG laser is used at high power settings and for a long time, the rise in temperature has deleterious effects on periodontal tissues. It is generally agreed that temperatures above $56-60^{\circ} \mathrm{C}$ cause denaturation of hard tissue proteins. ${ }^{25}$ Eriksson \& Albrektsson reported that $47^{\circ} \mathrm{C}$ temperature for 1 minute (only $10^{\circ} \mathrm{C}$ above human body temperature) produced persistant bone damage. ${ }^{26}$ Levy et al. demonstrated the level of energy is a critical factor to obtain safe treatment conditions. ${ }^{2}$ In our study we observed similar morphological changes when we used lower energy ( $2 \mathrm{~W}, 20 \mathrm{~Hz}, 100 \mathrm{~mJ}$ power) with India ink and higher energy (3.2 W, $20 \mathrm{~Hz}, 160 \mathrm{~mJ}$ power) without India ink. For inhibition of thermal damage, it might be advisable to use a laser initiator instead of increasing the output or duration.

\section{Conclusions}

As a result of our findings, we conclude the following:

1. Nd:YAG laser irradiation is effective on the removel of smear layer and debris, even without an initiator.

2. Pulsed Nd:YAG laser irradiation with the addition of Indian ink enhances melting and recrystallization of dentin as well as removal of smear layer and debris at the same settings.

3. Increased laser output increases the recrystallization.

For inhibition of thermal damage, it is advisable to use a laser initiator with Nd:YAG laser instead of increasing the output. 


\section{References}

1. Dederich DN, Zakariasen KL, Tulip J. Scanning electron microscopic analysis of canal wall dentin following neodymium-yttrium-aluminum-garnet laser irradiation. J Endod. 1984 Sep;10(9):428-31. No abstract available.

2. Levy G. Cleaning and shaping the root canal with a Nd:YAG laser beam : a comparative study. J Endodon 1992; 18:123-7

3. Berkiten M, Berkiten R, Okar I'. Comparative evaluation of antibacterial effects of Nd:YAG laser irradiation in root canals and dentinal tubules. J Endod. 2000 May;26(5):268-70.

4. Rooney J, Midda M, Leeming J. A laboratory investigation of the bactericidal effect of a NdYAG laser. Br Dent J. 1994 Jan 22;176(2):61-4.

5. Marques JLL, Eduardo CP, Matsumoto K. A study on morphological changes on the root canal walls lased by pulsed Nd:YAG laser. J Jpn Endod Assoc 1995; 16: 64-9

6. Saunders WP, Whitters CJ, Strang R, et. al. The effect of an Nd-YAG pulsed laser on the cleaning of the root canal and the formation of a fused apical plug. Int Endod J. 1995 Jul;28(4):213-20.

7. Morioka T, Suziki K, Tagomori S. Effects of beam absorptive mediators on an acid-resistance of surface enamel by Nd:YAG laser. J Dent Health 1984; 34:40-4

8. Zhang C, Kimura Y, Matsumoto K, et. al. Effects of pulsed Nd:YAG laser irradiation on root canal wall dentin with different laser initiators. J Endod. 1998 May;24(5):352-5.

9. Stabholz A, Khayat A, Weeks DA, et. al. Scanning electron microscopic study of the apical dentine surfaces lased with Nd:YAG laser following apicectomy and retrofill. Int Endod J. 1992 Nov;25(6):288-91.

10. Gutmann JL, Saunders WP, Nguyen L, et. al. Ultrasonic root-end preparation. Part 1. SEM analysis. Int Endod J. 1994 Nov;27(6):318-24.

11. Goya C, Yamazaki R, Tomita T, et. al. Effects of pulsed Nd:YAG laser irradiation on smear layer at the apical stop and apical leakage after obturation. Int Endod J. 2000 May;33(3):266-71.

12. Midda M, Renton-Harper P. Lasers in dentistry. Br Dent J. 1991 May 11;170(9):343-6.

13. Pick RM. Using lasers in clinical dental practice. J Am Dent Assoc. 1993 Feb;124(2):37-4. Review.

14. Chuck RS, Oz MC, Delohery TM, et. al. Dye-enhanced laser tissue welding. Lasers Surg Med. 1989;9(5):471-7.

15. Myers TD. Lasers in dentistry. J Am Dent Assoc. 1991 Jan;122(1):46-50. No abstract available.

16. Brooks SG, Ashley S, Fisher J, et. al.Exogenous chromophores for the argon and Nd:YAG lasers: a potential application to laser-tissue interactions. Lasers Surg Med. 1992;12(3):294-302.

17. White JM, Goodis HE, Marshall GW, et. al. Identification of the physical modification threshold of dentin induced by neodymium and holmium YAG lasers using scanning electron microscopy. Scanning Microsc. 1993 Mar;7(1):239-45; discussion 245-6.

18. McDonald A, Claffey NM, Pearson GJ, et. al. Effect of Nd:YAG radiation at millisecond pulse duration on dentine crater depth. Lasers Surg Med. 2000;27(3):213-23.

19. Dederich DN, Zakariasen KL, Tulip J. SEM analysis of dyed cana dentin following laser irradiation. J Dent Res 1985; 64(Special I'ssue):239

20. Ramsköld LO, Fong CD, Strömberg T. Thermal effects and antibacterial properties of energy levels required to sterilize stained root canals with an Nd:YAG laser. J Endod. 1997 Feb;23(2):96-100.

21. Stabholz A, Khayat A, Ravanshad S, et. al. Effects of Nd:YAG laser on apical seal of teeth after apicoectomy and retrofill. J Endod. 1992 Aug;18(8):371-5.

22. Pashley EL, Horner JA, Liu M, et. al. Effects of CO2 laser energy on dentin permeability. J Endod. 1992 Jun;18(6):257-62.

23. Wigdor H, Abt E, Ashrafi S, et. al. The effect of lasers on dental hard tissues. J Am Dent Assoc. 1993 Feb;124(2):65-70.

24. Vertucci FJ, Beatty RG. Apical leakage associated with retrofilling techniques: a dye study. J Endod. 1986 Aug;12(8):331-6. No abstract available.

25. Eriksson A, Albrektsson T, Grane B, et. al. Thermal injury to bone. A vital-microscopic description of heat effects. Int J Oral Surg. 1982 Apr;11(2):115-21.

26. Eriksson A, Albrektsson T. Temperature threshold levels for heat-induced bone tissue injury: a vitalmicroscopic study in the rabbit. J Prosthet Dent. 1983 Jul;50(1):101-7. No abstract available. 


\section{About the Authors}

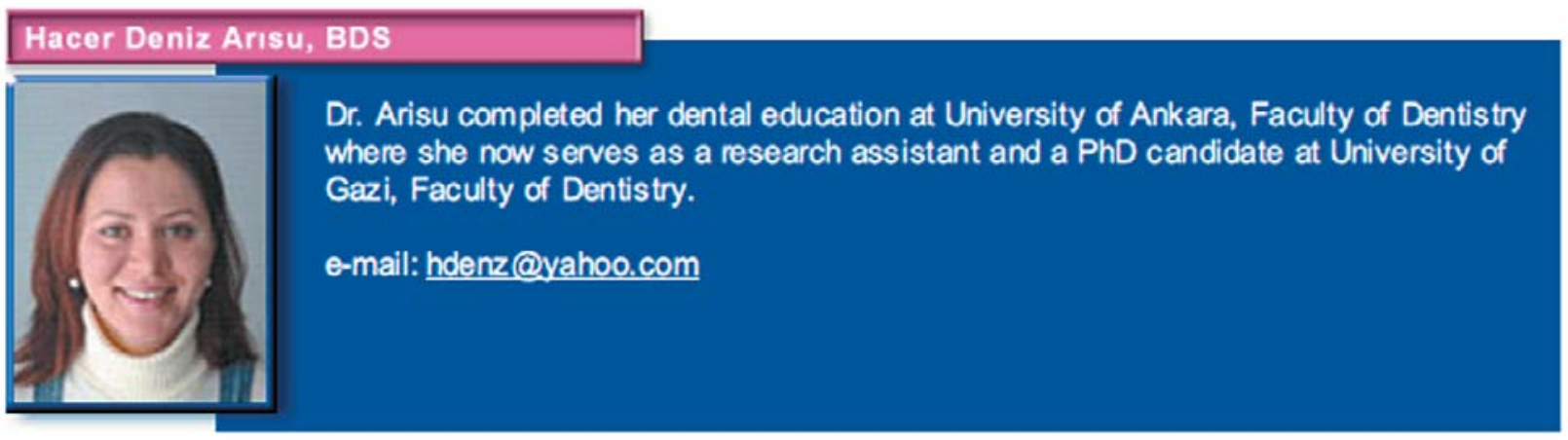

\section{Oya Bala, BDS, PhD}

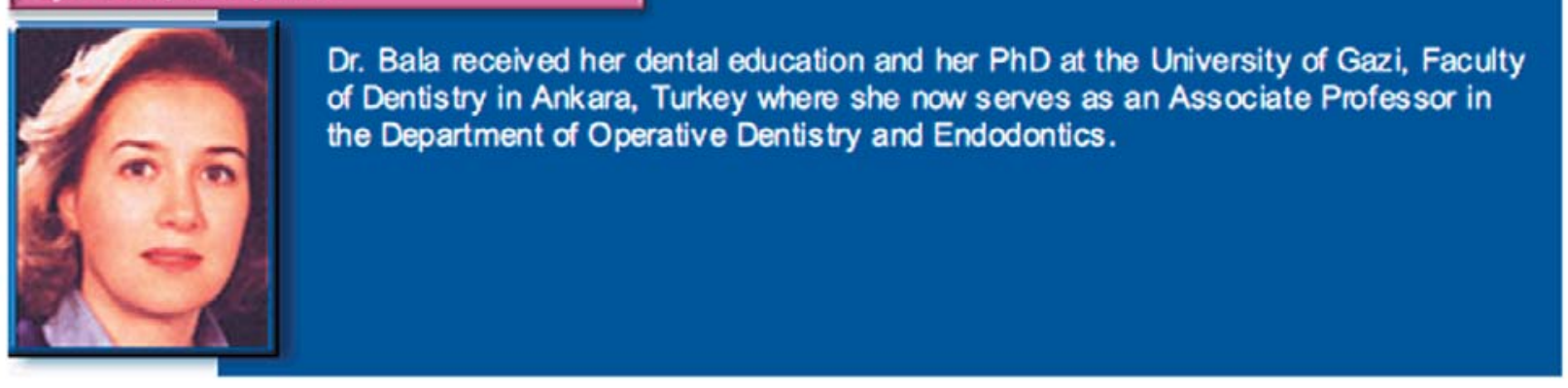

\section{Goulnara Alimzhanova, BDS}

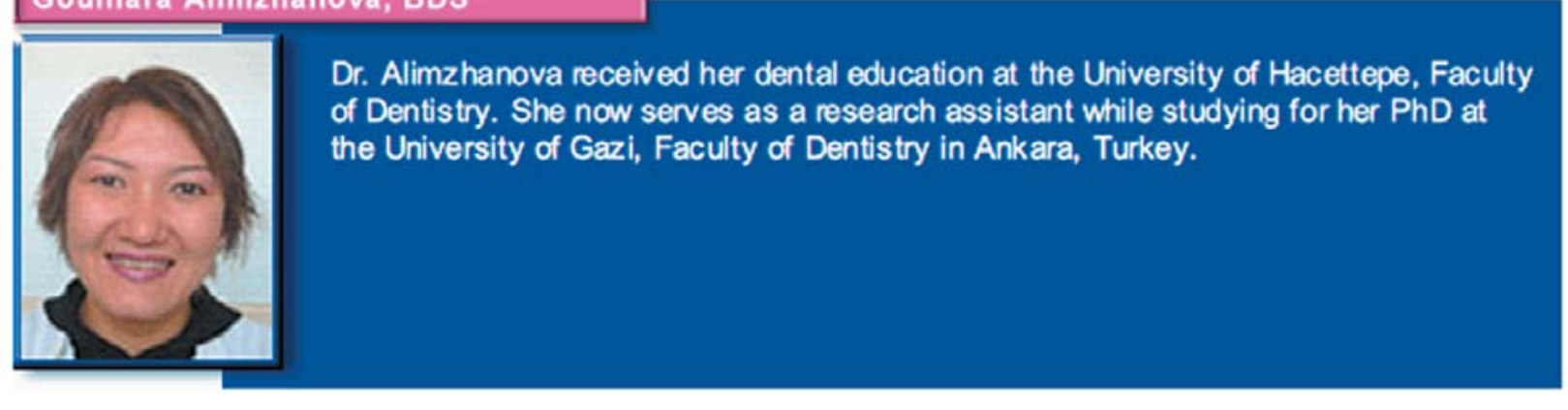

\section{Emin Turk8z, BDS, PhD}

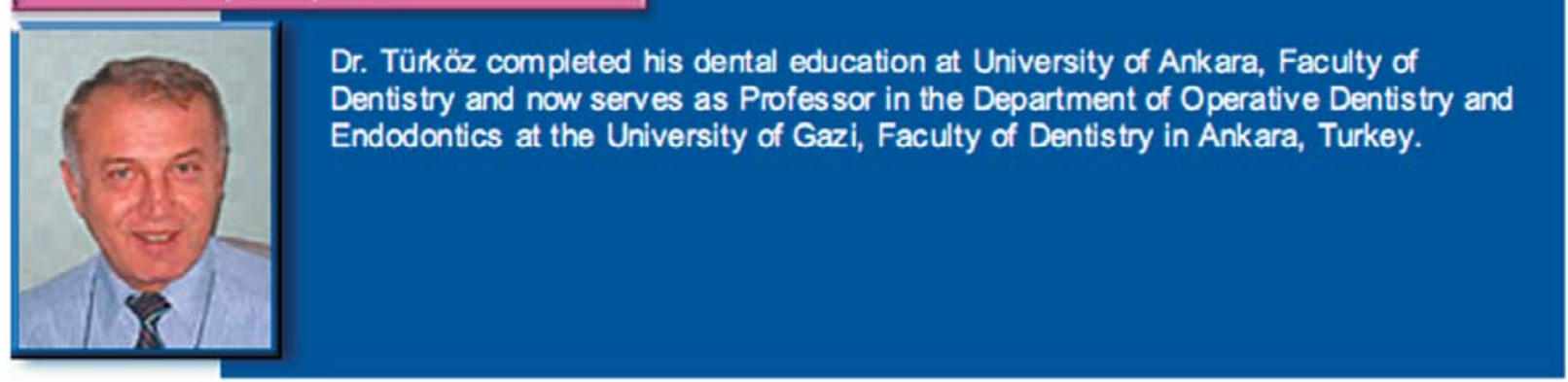

